\title{
Probabilistic Analysis of a Computer System with Inspection and Priority for Repair Activities of H/W over Replacement of S/W
}

\author{
Jyoti Anand \\ Department of Statistics \\ M.D.University,Rohtak-124001 \\ Haryana (India)
}

\author{
S.C.Malik \\ Department of Statistics \\ M.D.University,Rohtak-124001 \\ Haryana (India)
}

\begin{abstract}
The main aim of this paper is to carry out the probabilistic analysis of a computer system of two identical units in which one is operative and the other is in cold standby. In each unit $\mathrm{h} / \mathrm{w}$ and $\mathrm{s} / \mathrm{w}$ components fail independently and work together. A server visits the system immediately to inspect the $\mathrm{h} / \mathrm{w}$ components at their failure to see the feasibility of repair. If repair of the $\mathrm{h} / \mathrm{w}$ is not feasible, it is replaced by new one in the unit. However, only replacement of the $\mathrm{s} / \mathrm{w}$ components is made by new one at their failure. Priority to the replacement and repair of the $\mathrm{h} / \mathrm{w}$ components is given over the replacement of the s/w components. All the failure time distributions are assumed to be negative exponential while that of inspection, repair and replacement times are taken as arbitrary. Some reliability and economic measures of system effectiveness are evaluated using semi-Markov process and regenerative point technique. The graphs are drawn for a particular case to show the behavior of MTSF, availability and profit of the system models.
\end{abstract}

\section{General Terms}

Reliability and Economic Measures

\section{Keywords}

Computer System, Hardware and Software Failures, Feasibility of Repair, Priority for Replacement, Repair and Inspection, Probabilistic Analysis.

\section{INTRODUCTION}

In spite of increasing development and availability of new computer technologies, a little work has been dedicated to the probabilistic analysis of a computer system with independent failure of $\mathrm{h} / \mathrm{w}$ and $\mathrm{s} / \mathrm{w}$ components. And, most of the research work in the subject of $\mathrm{h} / \mathrm{w}$ and $\mathrm{s} / \mathrm{w}$ reliability has been limited to consideration of either $\mathrm{h} / \mathrm{w}$ subsystem alone or $\mathrm{s} / \mathrm{w}$ subsystem alone. Friedman and Tran [1] and Wilke et al. [2] tried to establish a combined reliability model for the whole system introducing both $\mathrm{h} / \mathrm{w}$ and $\mathrm{s} / \mathrm{w}$ under the assumption that $\mathrm{h} / \mathrm{w}$ and $\mathrm{s} / \mathrm{w}$ subsystems are independent to each other. Recently, Malik and Anand et al.[3,4] have suggested some reliability models of a computer system with independent $h / w$ and $\mathrm{s} / \mathrm{w}$ failures. In these models replacement of the components by new one is made in negligible time if inspection reveals that repair of $\mathrm{h} / \mathrm{w}$ components is not feasible. However, in paper [4], priority for the replacement at $\mathrm{s} / \mathrm{w}$ component is also made by new one over repair and replacement activities of $\mathrm{h} / \mathrm{w}$ failures. But the concept of priority to repair activities of the $\mathrm{h} / \mathrm{w}$ over replacement of the $\mathrm{s} / \mathrm{w}$ has not been studied so far by any researcher in the subject of reliability.
In view of above, the present paper deals with the probabilistic analysis of a computer system considering the concepts of priority for the replacement and repair of the $h / w$ components subject to inspection over replacement of the s/w. For this, a probabilistic model is developed by taking two identical units of a computer system. Initially, one unit is operative and other is kept as cold standby. Each unit has direct independent complete failure from the normal mode. There is a single server who visits the system immediately to do inspection. If repair of the defective $\mathrm{h} / \mathrm{w}$ components is not feasible, it is replaced by new one. However, only replacement of the s/w components is made by new one whenever they fail. The priority is given to replacement and repair of the $h / w$ components subject to inspection over replacement of the s/w components at their failure. The failure, repair and inspection time are taken as independent and uncorrelated random variables. The failure time of the unit follow negative exponential distributions while that of repair, inspection and replacement $\mathrm{s} / \mathrm{w}$ and $\mathrm{h} / \mathrm{w}$ are taken as arbitrary. To analyze the system probabilistically in detail, expression for some reliability characteristics such as mean sojourn times, mean time to system failure (MTSF), availability, busy period of the server due to $\mathrm{h} / \mathrm{w}$ failure or due to $\mathrm{s} / \mathrm{w}$ failure, expected no. of replacement due to $\mathrm{h} / \mathrm{w}$ failure or due to s/w failures \& expected no. of visits by the server are derived by making use of semi-Markov process and regenerative point technique. The graphs are drawn for a particular case to show the behavior of MTSF, availability and profit of the system models.

\section{NOTATIONS}

E : The set of regenerative states

$\mathrm{O} \quad$ : The unit is operative and in normal mode

cs : The unit is cold standby

$\mathrm{a} / \mathrm{b} \quad:$ Probability that the system has hardware /

software failure

$\lambda_{1} / \lambda_{2} \quad:$ Constant hardware / software failure rate

$\mathrm{p} / \mathrm{q} \quad$ : Probability that repair of the unit due to hardware failure is not feasible / feasible

FHUr/FHUR : The unit is failed due to hardware and is under repair /under repair continuously from previous state 
FHUi/FHUI : The unit is failed due to hardware and is under inspection/ under inspection continuously from previous state

FHWi/FHWI : The unit is failed due to hardware and is waiting for inspection/ waiting for inspection continuously from previous state

FSURp/FSURP : The unit is failed due to the software and is under replacement/under replacement continuously from previous state

FHWRp/FHWRP : The unit is failed due to the hardware and is waiting for replacement/waiting for replacement continuously from previous state

$\mathrm{h}(\mathrm{t}) / \mathrm{H}(\mathrm{t}) \quad$ : pdf / cdf of inspection time of unit due to hardware failure

$\mathrm{f}(\mathrm{t}) / \mathrm{F}(\mathrm{t}) \quad$ : pdf / pdf of replacement time of the software

$\mathrm{g}(\mathrm{t}) / \mathrm{G}(\mathrm{t}) \quad$ : pdf / cdf of repair time of the unit due to hardware failure

$\mathrm{q}_{\mathrm{ij}} / \mathrm{Q}_{\mathrm{ij}}(\mathrm{t}) \quad$ : pdf / cdf of passage time from regenerative state $\mathrm{i}$ to a regenerative state $\mathrm{j}$ or to a failed state $\mathrm{j}$ without visiting any other regenerative state in $(0, \mathrm{t}]$

$\mathrm{q}_{\mathrm{ij} . \mathrm{kr}} / \mathrm{Q}_{\mathrm{ij} . \mathrm{kr}}$

: pdf/cdf of direct transition time from regenerative state $i$ to a regenerative state $\mathrm{j}$ or to a failed state $\mathrm{j}$ visiting state $\mathrm{k}, \mathrm{r}$ once in $(0, \mathrm{t}]$

$\mathrm{m}_{\mathrm{ij}} \quad$ : Contribution to mean sojourn time $\left(\mu_{\mathrm{i}}\right)$ in state $S_{i}$ when system transits directly to state $\mathrm{S}_{\mathrm{j}}$ so that $\mu_{i}=\sum_{j} m_{i j}$ and $\mathrm{m}_{\mathrm{ij}}=\int t d Q_{i j}(t)=-q_{i j}^{*}(0)$
(S)/(C)

: Symbol for Laplace-Stieltjes convolution/Laplace convolution : Symbol for Laplace Steiltjes Transform (LST) / Laplace Transform (LT)

' (desh) : Used to represent alternative result

The following are the possible transition states of the system: The following are the possible transition states of the system: $\mathrm{S}_{0}=(\mathrm{O}, \mathrm{cs}), \mathrm{S}_{1}=(\mathrm{O}, \mathrm{FHUi}), \mathrm{S}_{2}=(\mathrm{O}, \mathrm{FSURp})$,

$\mathrm{S}_{3}=(\mathrm{O}, \mathrm{FHUr}), \mathrm{S}_{4}=($ FSURP, FSWRp $), \mathrm{S}_{5}=($ FHUI, FHWi $)$,

$\mathrm{S}_{6}=($ FHUR, FHWi $), \mathrm{S}_{7}=($ FHUr, FHWi $)$,

$\mathrm{S}_{8}=($ FHUI, FSWRp $), \mathrm{S}_{9}=($ FHUr, FSWRP $)$,

$\mathrm{S}_{10}=($ FHUR, FSWRp$)$,

The state $S_{0}-S_{3}, S_{11}$ are regenerative states while the states $S_{4}$ $-S_{10}, S_{12}$ are non-regenerative as shown in figure 1

\section{RELIABILITY INDICES 3.1 Transition Probabilities and Mean Sojourn Times}

Simple probabilistic considerations yield the following expressions for the non-zero elements

$p_{i j}=Q_{i j}(\infty)=\int_{0}^{\infty} q_{i j}(t) d t$ by taking all distributions exponential

i.e. $\mathrm{h}(\mathrm{t})=\theta_{1} e^{-\theta_{1} t}, \mathrm{f}(\mathrm{t})=\theta e^{-\theta t}$ and $\mathrm{g}(\mathrm{t})=\alpha e^{-\alpha t}$ :

$\mathrm{p}_{01}=\frac{a \lambda_{1}}{a \lambda_{1}+b \lambda_{2}}, \mathrm{p}_{02}=\frac{b \lambda_{2}}{a \lambda_{1}+b \lambda_{2}}, \quad p_{13}=\frac{q \theta_{1}}{a \lambda_{1}+b \lambda_{2}+\theta_{1}}$,

$p_{15}=\frac{a \lambda_{1}}{a \lambda_{1}+b \lambda_{2}+\theta_{1}}, p_{11.5}=\frac{p a \lambda_{1}}{a \lambda_{1}+b \lambda_{2}+\theta_{1}}$,

$p_{11.57}=\frac{q a \lambda_{1}}{a \lambda_{1}+b \lambda_{2}+\theta_{1}}, p_{12.8,12}=\frac{p b \lambda_{2}}{a \lambda_{1}+b \lambda_{2}+\theta_{1}}$,

$p_{12.89}=\frac{q b \lambda_{2}}{a \lambda_{1}+b \lambda_{2}+\theta_{1}}, p_{20}=\frac{\theta}{a \lambda_{1}+b \lambda_{2}+\theta}$,

$p_{24}=\frac{b \lambda_{2}}{a \lambda_{1}+b \lambda_{2}+\theta_{1}}, p_{2,11}=\frac{a \lambda_{1}}{a \lambda_{1}+b \lambda_{2}+\theta_{1}}$,

$p_{22.4}=\frac{b \lambda_{2}}{a \lambda_{1}+b \lambda_{2}+\theta_{1}}, p_{36}=\frac{a \lambda_{1}}{a \lambda_{1}+b \lambda_{2}+\alpha}$, 
$p_{3,10}=\frac{b \lambda_{2}}{a \lambda_{1}+b \lambda_{2}+\alpha}, p_{31.6}=\frac{a \lambda_{1}}{a \lambda_{1}+b \lambda_{2}+\alpha}$,

$p_{32.10}=\frac{b \lambda_{2}}{a \lambda_{1}+b \lambda_{2}+\alpha}, p_{11,2}=p, p_{11,2.9}=q$

It can be easily verified that

$\mathrm{p}_{01}+\mathrm{p}_{02}=\mathrm{p}_{10}+\mathrm{p}_{13}+\mathrm{p}_{15}+\mathrm{p}_{18}=\mathrm{p}_{20}+\mathrm{p}_{24}+\mathrm{p}_{2,11}=\mathrm{p}_{30}+\mathrm{p}_{36}+\mathrm{p}_{3,10}=\mathrm{p}_{11,2}+\mathrm{p}_{1}$

${ }_{1,9}=\mathrm{p}_{10}+\mathrm{p}_{13}+\mathrm{p}_{11.5}+\mathrm{p}_{11.57}+\mathrm{p}_{12.8,12}+\mathrm{p}_{12.89}=\mathrm{p}_{30}+\mathrm{p}_{31.6}+\mathrm{p}_{32.10=}$

$\mathrm{p}_{11,2}+\mathrm{p}_{11,2.9}=1$

The mean sojourn times $\left(\mu_{\mathrm{i}}\right)$ is the state $\mathrm{S}_{\mathrm{i}}$ are

$\mu_{0}=\frac{1}{a \lambda_{1}+b \lambda_{2}}, \mu_{1}=\frac{1}{a \lambda_{1}+b \lambda_{2}+\theta_{1}}$,

$\mu_{2}=\frac{1}{a \lambda_{1}+b \lambda_{2}+\theta}, \mu_{3}=\frac{1}{a \lambda_{1}+b \lambda_{2}+\alpha}$,

$\mu_{11}=\frac{1}{\theta_{1}}$,

Also

$m_{0}+m_{02}=\mu_{0}, \quad m_{10}+m_{13}+m_{15}+m_{18}=\mu_{1}$,

$m_{20}+m_{24}+m_{2,11}=\mu_{2}, m_{30}+m_{36}+m_{3,10}=\mu_{3}$,

$m_{11,2}+m_{11,9}=\mu_{11}$

And

$m_{10}+m_{10}+m_{11.5}+m_{11.57}+m_{12.8,12}+m_{12.89}=\mu_{1}^{\prime}(s a y)$

$m_{20}+m_{22.4}+m_{21.11}=\mu_{2}^{1}(s a y)$

$m_{30}+m_{36}+m_{32.10}=\mu_{3}^{1}$ (say)

For $\mathrm{h}(\mathrm{t})=\theta_{1} e^{-\theta_{1} t}, \mathrm{f}(\mathrm{t})=\theta e^{-\theta t}$ and $\mathrm{g}(\mathrm{t})=\alpha e^{-\alpha t}$, we have

$m_{1}^{1}=\frac{q_{1} a+\left(a l_{1}+b l_{2}\right) a+\left(a l_{1}+b l_{2}\right) q q_{1}}{q_{1} a\left(a l_{1}+b l_{2}+q_{1}\right)}, \mu_{2}^{1}=\frac{1}{\theta}$,

$\mu_{3}^{1}=\frac{1}{\alpha}$

\subsection{Reliability and Mean Time to System Failure (Mtsf)}

Let $\phi_{\mathrm{i}}(\mathrm{t})$ be the cdf of first passage time from regenerative state $\mathrm{i}$ to a failed state. Regarding the failed state as absorbing state, we have the following recursive relations for $\phi_{\mathrm{i}}(\mathrm{t})$ :

$\phi_{i}(t)=\sum_{j} Q_{i j}(t) \$ \phi_{j}(t)+\sum_{k} Q_{i k}(t)$

Where $\mathrm{j}$ is an un-failed regenerative state to which the given regenerative stat $\mathrm{I}$ can transit and $\mathrm{k}$ is a failed state to which the state I can transit directly.

Taking LST of above relation (7) and solving for $\tilde{f}_{0}(s)$

We have

$\mathrm{R} *(\mathrm{~s})=\frac{1-\tilde{f}_{0}(s)}{s}$

The reliability of the system model can be obtained by taking Laplace inverse transform of (8).

The mean time to system failure (MTSF) is given by

$\mathrm{MTSF}=\lim _{s \rightarrow o} \frac{1-\tilde{\phi}_{0}(s)}{s}=\frac{N_{1}}{D_{1}}$

where

$\mathrm{N}_{1}=\mu_{0}+p_{01} \mu_{0}+p_{02} \mu_{2}+p_{01} p_{13} \mu_{3}$

$\mathrm{D}_{1}=1-p_{01}\left(p_{10}+p_{13} p_{30}\right)-p_{02} p_{20}$

\subsection{Steady State Availability}

Let $A_{i}(t)$ be the probability that the system is in up-state at instant ' $t$ ' given that the system entered regenerative state $i$ at $t=0$. The recursive relations for $A_{i}(t)$ are given as

$A_{i}(t)=M_{i}(t)+\sum_{j} q_{i j}^{n}(t)(c) A_{j}(t)$

Where $\mathrm{j}$ is any successive regenerative state to which the regenerative stste $I$ can transit through $n \geq 1$ (natural number) transitions. $\mathrm{M}_{\mathrm{i}}(\mathrm{t})$ is the probability that the system is up initially in state $S_{i} \in E$ is up at time t without visiting to any other regenerative state, we have

$$
M_{0}(t)=e^{-\left(a \lambda_{1}+b \lambda_{2}\right) t}, \quad M_{1}(t)=e^{-\left(a \lambda_{1}+b \lambda_{2}\right) t} \bar{H}(t),
$$


$M_{2}(t)=e^{-\left(a \lambda_{1}+b \lambda_{2}\right) t} \bar{F}(t), \quad M_{3}(t)=e^{-\left(a \lambda_{1}+b \lambda_{2}\right) t} \bar{G}(t)$

Taking LT of above relations (10) and solving for $A_{0}^{*}(s)$, the steady state availability is given by

$A_{0}(\infty)=\lim _{s \rightarrow 0} s A_{0}^{*}(s)=\frac{N_{2}}{D_{2}}$

where

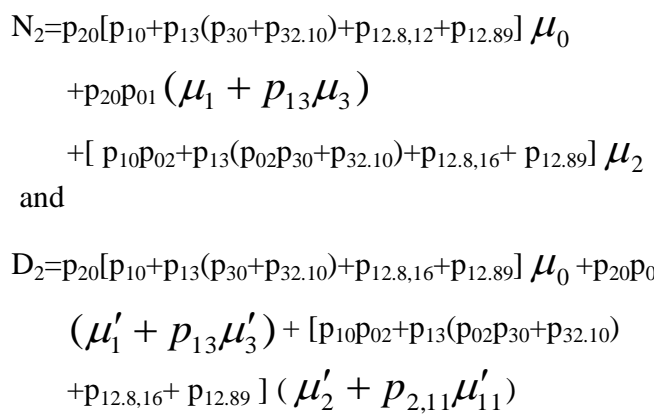

\subsection{Busy Period Analysis for Server}

\section{(a) Due to Hardware Failure}

Let $\mathrm{B}_{\mathrm{i}}{ }^{\mathrm{H}}(\mathrm{t})$ be the probability that the server is busy in repairing the unit due to hardware failure at an instant ' $t$ ' given that the system entered state $i$ at $t=0$. The recursive relations for $\mathrm{B}_{\mathrm{i}}^{\mathrm{H}}(\mathrm{t})$ are as follows:

$$
B_{i}^{H}(t)=W_{i}^{H}(t)+\sum_{j} q_{i j}^{n}(t) \theta B_{j}^{H}(t)
$$

where $\mathrm{W}_{\mathrm{i}}^{\mathrm{H}}(\mathrm{t})$ be the probability that the server is busy in state $\mathrm{S}_{\mathrm{i}}$ due to hardware failure upto time $\mathrm{t}$ without making any transition to any other regenerative state or returning to the same via one or more non-regenerative states and so

$$
\begin{aligned}
& W_{1}^{H}(t)=e^{-\left(a \lambda_{1}+b \lambda_{2}\right) t} \bar{H}(t)+\left[a \lambda_{1} e^{-\left(a \lambda_{1}+b \lambda_{2}\right)} @ \mathrm{qh}(\mathrm{t}) @ 1\right] \bar{G}(t) \\
& +\left(b \lambda_{2} e^{-\left(a \lambda_{1}+b \lambda_{2}\right) t} @ q h(t) @ 1\right) \overline{G(t)}+\left(b \lambda_{2} e^{-\left(a \lambda_{1}+b \lambda_{2}\right) t} @ q h(t) \subseteq 1\right) \overline{F(t)} \\
& W_{3}^{H}(t)=e^{-\left(a \lambda_{1}+b \lambda_{2}\right) t} \bar{G}(t)+\left[a \lambda_{1} e^{-\left(a \lambda_{1}+b \lambda_{2}\right)} @ 1\right] \bar{G}(t) \\
& +\left[b \lambda_{2} e^{-\left(a \lambda_{1}+b \lambda_{2}\right) t} @ 1\right] \bar{G}(t) \\
& W_{11}^{H}(t)=\overline{H(t)}
\end{aligned}
$$

\section{(b) Due to replacement of the software}

Let $B_{i}^{S}(\mathrm{t})$ be the probability that the server is busy due to replacement of the software at an instant ' $t$ ' given that the system entered the regenerative state $\mathrm{i}$ at $\mathrm{t}=0$. We have the following recursive relations for $B_{i}^{S}(\mathrm{t}):(12)$

$B_{i}^{S}(t)=w_{i}^{S}(t)+\sum_{j} q_{i j}^{n}(t) \theta B_{j}^{S}(t)$

where $\mathrm{W}_{\mathrm{i}}^{\mathrm{S}}(\mathrm{t})$ be the probability that the server is busy in state $S_{i}$ due to replacement of the software up to time $t$ without making any transition to any other regenerative state or returning to the same via one or more non-regenerative states and so

$W_{2}^{H}(t)=e^{-\left(a \lambda_{1}+b \lambda_{2}\right) t} \overline{F(t)}+\left(b \lambda_{2} e^{-\left(a \lambda_{1}+b \lambda_{2}\right) t}\right.$ (C) 1$) \overline{F(t)}$

Taking LT of above relations (11) and (13) and solving for $B_{0}^{* H}(s)$ and $B_{0}^{* S}(s)$, the time for which server is busy due to repair and replacements respectively is given by

$$
\begin{aligned}
& B_{0}^{H}=\lim _{s \rightarrow 0} s B_{0}^{* H}(s)=\frac{N_{3}^{H}}{D_{2}} \quad \text { And } \\
& B_{0}^{S}=\lim _{s \rightarrow 0} s B_{0}^{* S}(s)=\frac{N_{3}^{S}}{D_{2}}
\end{aligned}
$$

where

$$
\begin{aligned}
& N_{3}^{H}=p_{01} p_{20}\left(\tilde{W}_{1}^{H}(0)+p_{13} \tilde{W}_{3}^{H}(0)\right)+p_{2,11}\left(p_{10} p_{02}+p_{12.8,12}\right. \\
& +p_{12.89}+p_{13}\left(p_{30} p_{02}+p_{32.10}\right) \tilde{W}_{11}^{H}(0) \\
& N_{3}^{S}=p_{2,11}\left(p_{10} p_{02}+p_{12.8,12}+p_{12.89}\right. \\
& +p_{13}\left(p_{30} p_{02}+p_{32.10}\right) \tilde{W}_{2}^{S}(0) \\
& \text { and } \mathrm{D}_{2} \text { is already mentioned. }
\end{aligned}
$$

\subsection{Expected Number Of Replacements Of The Units}

\section{(a) Due to Hardware Failure}

Let $\mathrm{R}_{\mathrm{i}}{ }^{\mathrm{H}}(\mathrm{t})$ be the expected number of replacements of the failed hardware components by the server in $(0, t]$ given that 
the system entered the regenerative state $i$ at $t=0$. The recursive relations for $\mathrm{R}_{\mathrm{i}}^{\mathrm{H}}(\mathrm{t})$ are given as

$R_{\mathrm{i}}^{H}(t)=\sum_{j} q_{i, j}^{n}(t)(\overline{0})\left[\delta_{j}+R_{j}^{H}(t)\right]$

Where $\mathrm{j}$ is any regenerative state to which the given regenerative state $I$ transits and $\delta_{\mathrm{j}}=1$, if $\mathrm{j}$ is the regenerative state where the server does job a fresh, otherwise $\delta_{\mathrm{j}}=0$.

\section{(b) Due to Software Failure}

Let $\mathrm{R}_{\mathrm{i}}^{\mathrm{S}}(\mathrm{t})$ be the expected number of replacements of the failed software by the server in $(0, t]$ given that the system entered the regenerative state $i$ at $t=0$. The recursive relations for $\mathrm{R}_{\mathrm{i}}^{\mathrm{S}}(\mathrm{t})$ are given as

$$
R_{\mathrm{i}}^{S}(t)=\sum_{j} q_{i j}^{\mathrm{n}}(t)\left[\delta_{0}+\mathbb{R}_{j}^{S}(\mathrm{t})\right]
$$

Where $\mathrm{j}$ is any regenerative state to which the given regenerative state I transits and $\delta_{\mathrm{j}}=1$, if $\mathrm{j}$ is the regenerative state where the server does job a fres

Taking LST of relations (16) and (17). And, solving for $\tilde{R}_{0}^{H}(s)$ and $\tilde{R}_{0}^{S}(s)$. The expected numbers of replacements per unit time to the hardware and software failures are respective of given by

$$
\begin{aligned}
& R_{0}^{H}(\infty)=\lim _{s \rightarrow 0} s \tilde{R}_{0}^{H}(s)=\frac{N_{4}^{H}}{D_{2}} \\
& \text { And } \quad R_{0}^{S}(\infty)=\lim _{s \rightarrow 0} s \tilde{R}_{0}^{S}(s)=\frac{N_{4}^{S}}{D_{2}}
\end{aligned}
$$

where

$N_{4}^{H}=\mathrm{p}_{01} \mathrm{p}_{20}\left(\mathrm{p}_{10}+\mathrm{p}_{12.8,12}+\mathrm{p}_{11.5}\right)+\mathrm{p}_{11,2}$

$p_{2,11}\left(p_{10} p_{02}+p_{12.8,12}+p_{12.89}+p_{13}\left(p_{30} p_{02}+p_{32.10}\right)\right)$

$N_{4}^{S}=\left(\mathrm{p}_{20}+\mathrm{p}_{22.4}\right)+\left[\mathrm{p}_{10} \mathrm{p}_{02}+\mathrm{p}_{13}\left(\mathrm{p}_{02} \mathrm{p}_{30}+\mathrm{p}_{32.10}\right)+\mathrm{p}_{12.8,16}+\mathrm{p}_{12.89}\right]$

and $\mathrm{D}_{2}$ is already mentioned.

\subsection{Expected Number of Visits by The Server}

Let $\mathrm{N}_{\mathrm{i}}(\mathrm{t})$ be the expected number of visits by the server in $(0$, $\mathrm{t}]$ given that the system entered the regenerative state $\mathrm{i}$ at $\mathrm{t}=$ 0 . The recursive relations for $\mathrm{N}_{\mathrm{i}}(\mathrm{t})$ are given as

$N_{i}(t)=\sum_{j} Q_{i j}^{n}(t)(1)\left[\delta_{j}+N_{j}(t)\right]$

Where $\mathrm{j}$ is any regenerative state to which the given regenerative state $I$ transits and $\delta_{j}=1$, if $\mathrm{j}$ is the regenerative state where the server does job afresh, otherwise $\delta_{\mathrm{j}}=0$.
Taking LST of relation (19) and solving for $\tilde{N}_{0}(s)$. The expected number of visit per unit time by the server are given by

$$
N_{0}(\infty)=\lim _{s \rightarrow 0} s \tilde{N}_{0}(s)=\frac{N_{5}}{D_{2}}
$$

where

$\mathrm{N}_{5}=\mathrm{p}_{20}\left[\mathrm{p}_{10}+\mathrm{p}_{13}\left(\mathrm{p}_{30}+\mathrm{p}_{32.10}\right)+\mathrm{p}_{12.8,12}+\mathrm{p}_{12.89}\right]$

and $\mathrm{D}_{2}$ is already specified.

\section{PROFIT ANALYSIS}

The profit incurred to the system model in steady state can be obtained as

$P=K_{0} A_{0}-K_{1} B_{0}^{H}-K_{2} B_{0}^{S}-K_{3} R_{0}^{H}-K_{4} R_{0}^{S}-K_{5} N_{0}$

where

$\mathrm{K}_{0}=$ Revenue per unit up-time of the system

$\mathrm{K}_{1}=$ Cost per unit time for which server is busy due to hardware failure

$\mathrm{K}_{2}=$ Cost per unit time for which server is busy due to software failure

$\mathrm{K}_{3}=$ Cost per unit replacement of the failed hardware component

$\mathrm{K}_{4}=$ Cost per unit replacement of the failed software $\mathrm{K}_{5}=$ Cost per unit visit by the server and defined.

$$
\boldsymbol{A}_{\mathrm{O}}, \boldsymbol{B}_{\mathrm{O}}^{H}, \boldsymbol{B}_{\mathrm{O}}^{S}, \boldsymbol{R}_{\mathrm{O}}^{H}, \boldsymbol{R}_{\mathrm{O}}^{S}, \boldsymbol{N}_{\mathrm{O}} \text { are already }
$$

\section{PARTICULAR CASE}

Suppose $\mathrm{g}(\mathrm{t})=a e^{-a t}, \mathrm{~h}(\mathrm{t})=q_{1} e^{-q_{1} t}, \mathrm{f}(\mathrm{t})=q e^{-q t}$

We can obtain the following results

$\operatorname{MTSF}\left(\mathrm{T}_{0}\right)=\frac{N_{1}}{D_{1}}$,

Availability $\left(\mathrm{A}_{0}\right)=\frac{N_{2}}{D_{2}}$

,Busy period due to hardware failure $\left(B_{0}^{H}\right)=\frac{N_{3}^{H}}{D_{2}}$

Busy period due to software failure $\quad\left(B_{0}^{S}\right)=\frac{N_{3}^{S}}{D_{2}}$, 
Expected number of replacements at hardware failure $\left(R_{0}^{H}\right)=\frac{N_{4}^{H}}{D_{2}}$

Expected number of replacements at software failure $\left(R_{0}^{S}\right)=\frac{N_{4}^{S}}{D_{2}}$

Expected number of visits by the server $\left(N_{0}\right)=\frac{N_{5}}{D_{2}}$

where

$$
\begin{aligned}
& N_{1}=\left[\left(a \lambda_{1}+b \lambda_{2}+\alpha\right)\left\{\begin{array}{l}
\left(a \lambda_{1}+b \lambda_{2}+\theta\right) \\
\left(2 a \lambda_{1}+b \lambda_{2}+\theta_{1}\right)+b \lambda_{2}\left(a \lambda_{1}+b \lambda_{2}+\theta_{1}\right)
\end{array}\right\}\right. \\
& \left.+a \lambda_{1} q \theta_{1}\left(a \lambda_{1}+b \lambda_{2}+\theta\right)\right] / R_{1} \\
& D_{1}=\left(a \lambda_{1}+b \lambda_{2}+\theta_{1}\right)\left(a \lambda_{1}+b \lambda_{2}+\alpha\right) \\
& {\left[a \lambda_{1}\left(a \lambda_{1}+b \lambda_{2}+\theta\right)+b \lambda_{2}\left(a \lambda_{1}+b \lambda_{2}\right)\right]} \\
& -\mathrm{a} \lambda_{1} \theta_{1}\left(a \lambda_{1}+b \lambda_{2}+\theta\right)\left[p\left(a \lambda_{1}+b \lambda_{2}+\alpha\right)\right] / R_{1} \\
& R_{1}=\left(a \lambda_{1}+b \lambda_{2}\right)\left(a \lambda_{1}+b \lambda_{2}+\theta\right)\left(a \lambda_{1}+b \lambda_{2}+\theta_{1}\right) \\
& \left(a \lambda_{1}+b \lambda_{2}+\alpha\right) \\
& D_{2}=\left[( a \lambda _ { 1 } + b \lambda _ { 2 } + \alpha ) \left[\alpha \theta_{1} \theta\left(p\left(a \lambda_{1}+\theta\right)+\theta_{1} a \lambda_{1}\right)+\left(a \lambda_{1}+b \lambda_{2}+\theta\right)\right.\right. \\
& \left.\left(a \lambda_{1}\left(\theta_{1} \theta\left(\alpha+q \theta_{1}\right)+\left(a \lambda_{1}+b \lambda_{2}\right)\left(\theta_{1}\left(\alpha+q \theta_{1}\right) \alpha \theta_{1}\right)\right)\right)\right]+\alpha \theta_{1}^{2} \theta q \\
& \left.\left(\alpha\left(a \lambda_{1}+\theta\right)+b \lambda_{2}\right)\right] / \alpha \theta_{1} \theta R_{1} \\
& N_{2}=\left[\left(a \lambda_{1}+b \lambda_{2}+\alpha\right)\left[\begin{array}{l}
p \theta_{1}\left(a \lambda_{1}+\theta\right)+2 a \lambda_{1}\left(a \lambda_{1}+b \lambda_{2}+\theta\right) \\
+\theta_{1} b \lambda_{2}
\end{array}\right]\right. \\
& \left.+q \theta_{1}\left(a \lambda_{1}\left(a \lambda_{1}+b \lambda_{2}+\theta\right)+\left(a \lambda_{1}+\theta\right) \alpha+b \lambda_{2}\right)\right] / R_{1} \\
& a \lambda_{1}\left[\theta_{1} \alpha\left(\theta_{1}-a \lambda_{1}-b \lambda_{2}\right)\left(a \lambda_{1}+b \lambda_{2}+\alpha\right)\right. \\
& \left(a \lambda_{1}+b \lambda_{2}\right)+q \theta_{1} \alpha^{2}-q\left(a \lambda_{1}+b \lambda_{2}+\alpha\right) \theta_{1} \alpha \\
& -q\left(a \lambda_{1}+b \lambda_{2}+\alpha\right)\left(a \lambda_{1}+b \lambda_{2}\right)\left(\theta_{1}-a \lambda_{1}-b \lambda_{2}\right) \\
& N_{3}^{H}=\frac{\left(a \lambda_{1}+b \lambda_{2}+\alpha\right)\left(a \lambda_{1}+b \lambda_{2}\right)}{\theta_{1} \alpha\left(a \lambda_{1}+b \lambda_{2}+\theta_{1}\right)} \\
& \left(\theta_{1}-a \lambda_{1}-b \lambda_{2}\right)\left(a \lambda_{1}+b \lambda_{2}+\alpha\right)\left(a \lambda_{1}+b \lambda_{2}\right)^{2}
\end{aligned}
$$

$$
\begin{aligned}
& N_{3}^{S}=\frac{a \lambda_{1}\left(a \lambda_{1}+b \lambda_{2}\right)+\theta_{1} b \lambda_{2}}{\theta\left(a \lambda_{1}+b \lambda_{2}+\theta_{1}\right)\left(a \lambda_{1}+b \lambda_{2}\right)} \\
& N_{4}^{H}=\frac{p a \lambda_{1}}{\left(a \lambda_{1}+b \lambda_{2}\right)}, N_{4}^{S}=\frac{a \lambda_{1}\left(a \lambda_{1}+b \lambda_{2}\right)+\theta_{1} b \lambda_{2}}{\left(a \lambda_{1}+b \lambda_{2}\right)\left(a \lambda_{1}+b \lambda_{2}+\theta_{1}\right)} \\
& N_{5}=\frac{a \lambda_{1}\left[q\left\{\theta_{1} \alpha\left(a \lambda_{1}+\theta\right)+\theta \theta_{1} b \lambda_{2}\right\}+a \lambda_{1} \theta\left(a \lambda_{1}+b \lambda_{2}+\alpha\right)\right]}{R_{1}}
\end{aligned}
$$

\section{CONCLUSION}

In the present study, the numerical results considering a particular case are obtained to carry out the profit analysis of a computer system by giving the priority to repair activities of $h / w$ components over replacement of $s / w$ components. Using these results, the graphs for mean time to system failure (MTSF), availability and profit are drawn with respect to $\mathrm{h} / \mathrm{w}$ failure rate $\left(\lambda_{2}\right)$ for fixed values of other parameters as shown respectively in figures $2^{\text {nd }}, 3^{\text {rd }}$ and $4^{\text {th }}$. From these figures, it is concluded that MTSF deceases with the increase of $h / w$ and $s / w$ failures rates. However, MTSF goes on increasing as repair rate $(\alpha)$, replacement rate $(\theta)$ of the unit at $\mathrm{s} / \mathrm{w}$ failure and replacement rate $\left(\theta_{1}\right)$ of the unit at $\mathrm{h} / \mathrm{w}$ failure increase. The results obtained for availability and profit indicate that the value of these measures decrease with increase of $\mathrm{h} / \mathrm{w}$ and $\mathrm{s} / \mathrm{w}$ failure rate $\left(\lambda_{1}\right)$ and $\left(\lambda_{2}\right)$ respectively. But their values increase if repair rate $(\alpha)$ and replacement rates $(\theta)$ and $\left(\theta_{1}\right)$ increase.

Thus it is concluded that the concept of priority given to the replacement and repair of $\mathrm{h} / \mathrm{w}$ components over replacement of s/w components is not much economically beneficial as compare to the system in which no such priority is given. 
State Transition Diagram

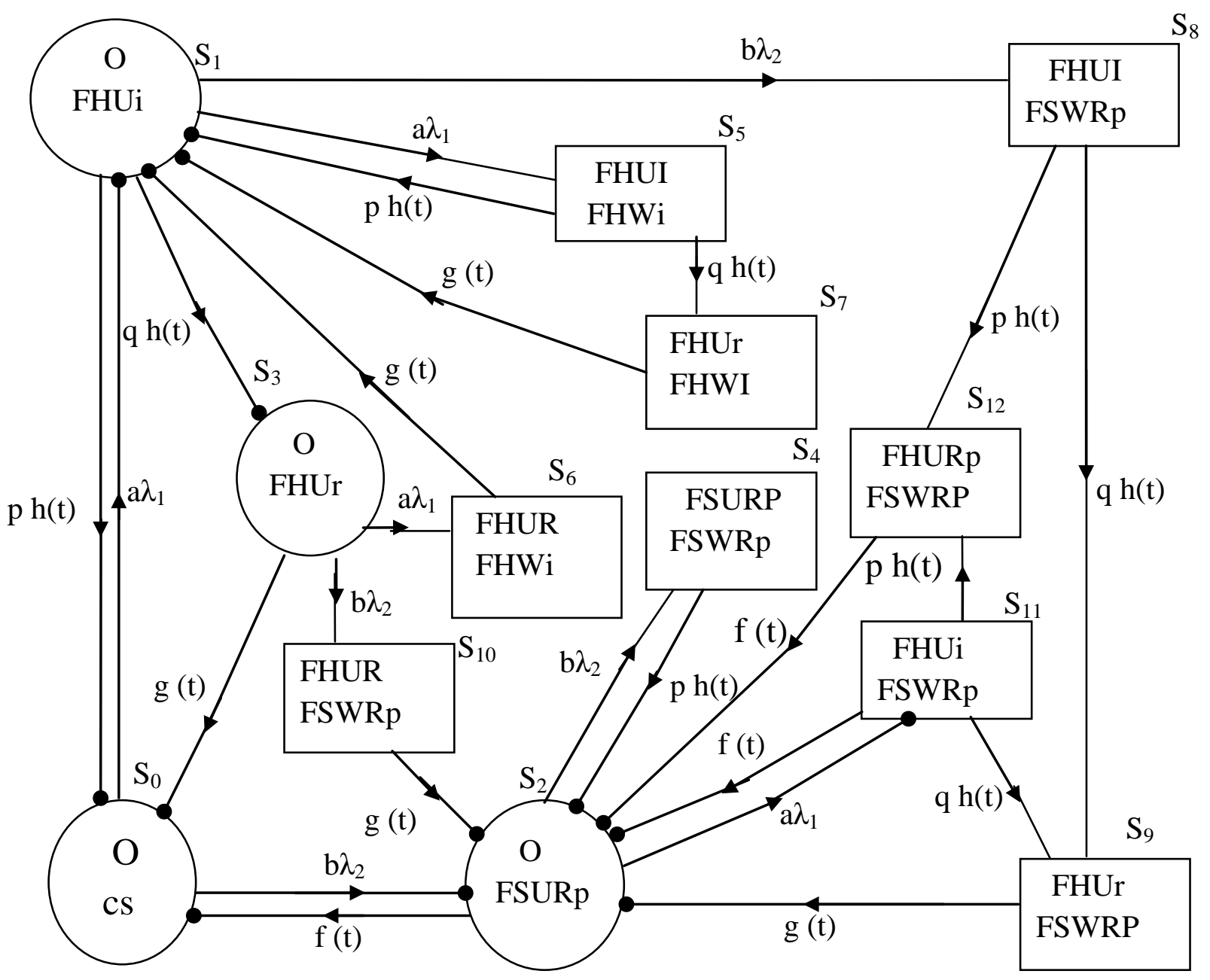

Fig. 1

$\bigcirc$ Up-state

$\square$ Failed state

- Regenerative point 


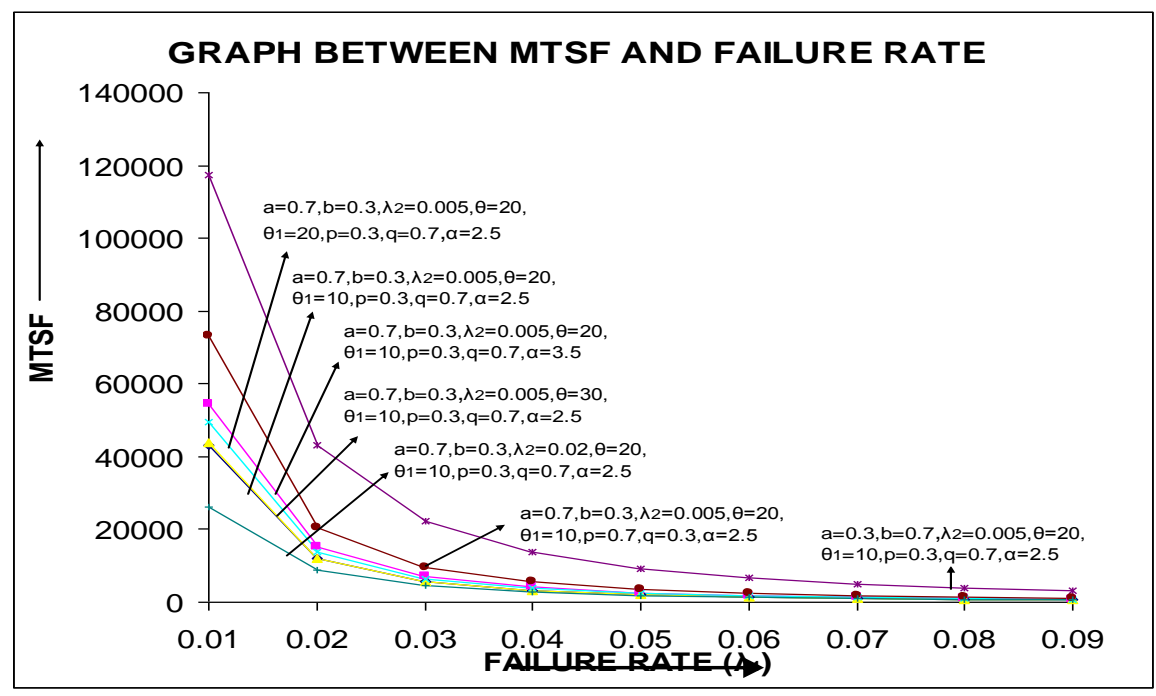

Fig.2

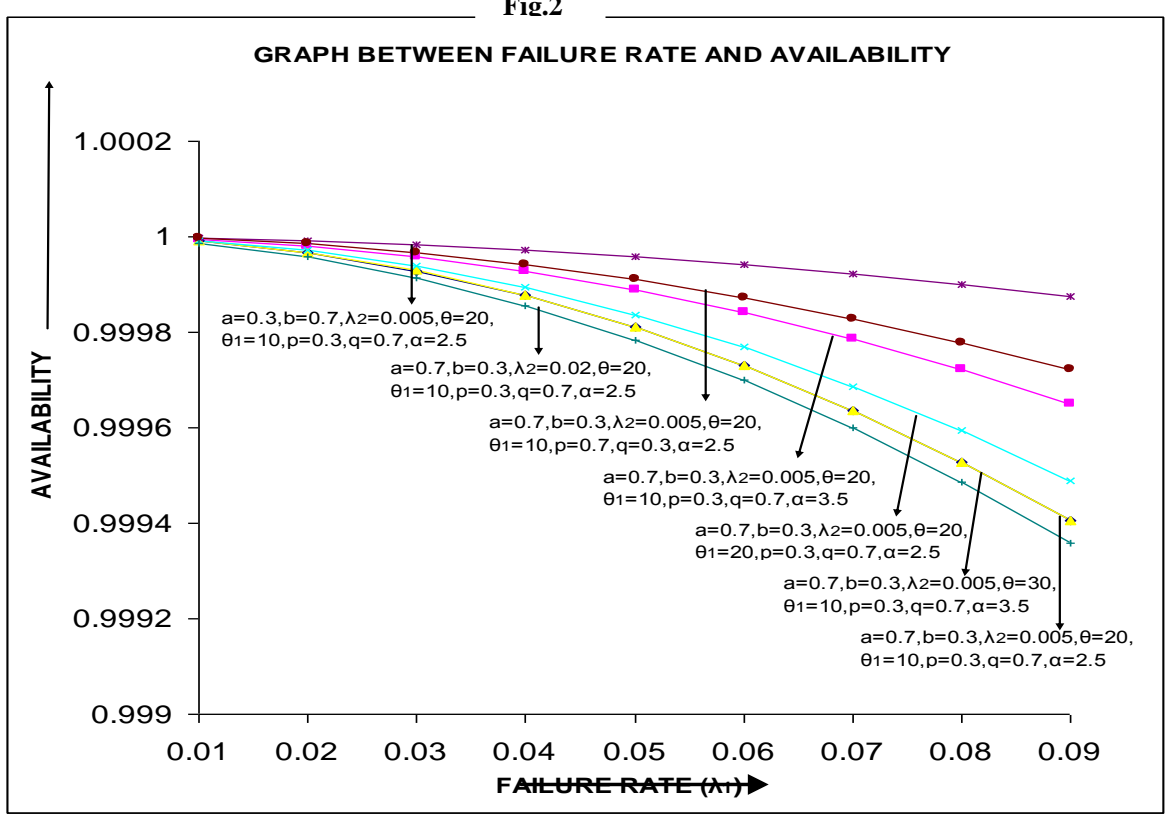

Fig.3

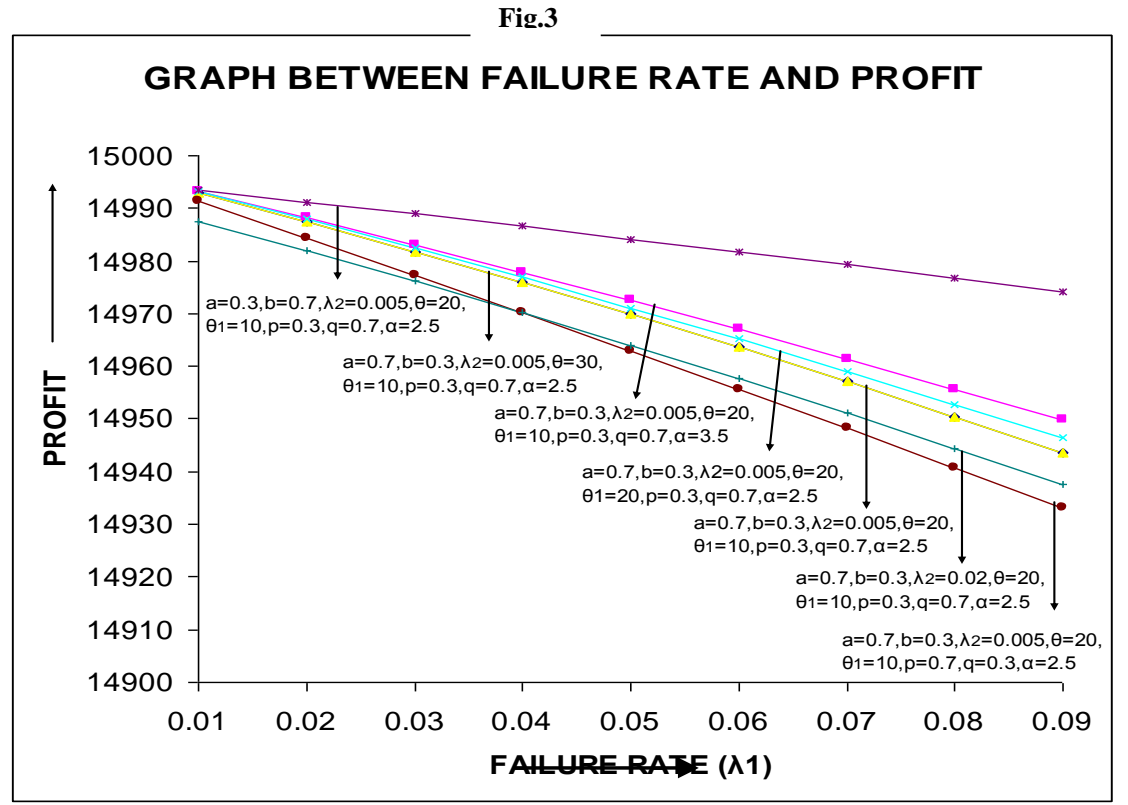

Fig 4. 


\section{REFERENCES}

[1] Friedman, M.A. and Tran, P. 1992: Reliability Techniques for Combined Hardware / Software Systems. Proceedings of Annual Reliability and Maintainability Symposium, pp. 209-293.

[2] Welke, S.R.; Johnson, B.W. and Aylar, J.H. 1995: Reliability Modeling of Hardware Software Systems. IEEE Transactions on Reliability, Vol. 44(3), pp. 413418

[3] Malik, S.C. and Anand, Jyoti 2010: Reliability And Economic Analysis of a Computer System With Independent H/W and S/W Failures. Bulletin of Pure and Applied Sciences (BPASS), Vol.29E(No.1),pp.141-153

[4] Malik, S.C. and Anand, Jyoti 2011: Reliability Modeling of a Computer System With Priority for Replacement at Software Failure over Repair Activities at H/W Failure.
International Journal of Statistics and System (IJSS), ISSN 0973-2675, Vol. 6(3),pp.315-325.

[5] Malik, S. C. and Ashish Kumar 2011. Profit Analysis of a Computer System with Priority to Software Replacement over Hardware Repair Subject to Maximum Operation and Repair Times, International Journal of Engineering Science \& Technology, Vol.3, No. 10, pp. 7452- 7468

[6] Lai, C.D.; Xie, M.; Poh, K.L.; Dai, Y.S. and Yang, P. 2002: A model for availability analysis of distributed software / hardware systems, Information and Software Technology, Vol. 44, pp. 343-350.

[7] Malik, S.C. 2008: Reliability modeling and profit analysis of a single-unit system with inspection by a server who appears and disappears randomly, Journal of Pure and Applied Mathematika Sciences, Vol. LXVII (12), pp. 135-146. 